\title{
74. Gravity Measurements along the Lines of Precise Levels over Whole Japan by Means of a WORDEN Gravimeter. III. Kinki District
}

\author{
By Chuji Tsubor, Akira Jitsukawa, and Hirokazu TaJima \\ Earthquake Research Institute, Tokyo University \\ (Comm. by M. Matuy Ama, M.J.A., July 13, 1953)
}

This is the third of the serial reports of our survey of the gravity values over whole Japan by means of a WORDEN gravimeter and is concerned with the results obtained in the Kinki district. This district lies to the east of the Chûgoku and Shikoku districts and occupies the middle western part of the main island of Japan. It is approximately $33,000 \mathrm{~km}^{2}$ in area and comprises seven prefectures, viz. Mie, Shiga, Kyôto, Ôsaka, Hyôgo, Nara and Wakayama. At 480 points in this district, the gravity values were measured. They are all bench marks except a few local meteorological stations and other identifiable points with known heights. The lines of precise levels along which the bench marks in this district are laid are shown in Fig. 1, together with prefecture boundaries. The number of points at which the measurements were made in each of the seven prefectures is as in the following table.

\begin{tabular}{ll|r}
\hline 23) & Mie & 89 \\
24) & Shiga & 48 \\
25) & Kyôto & 93 \\
26) & Ôsaka & 31 \\
27) & Hyôgo & 93 \\
28) & Nara & 30 \\
29) & Wakayama & 96 \\
\hline & Total & 480
\end{tabular}

The survey was made in June, July, November and December, 1951, and partly in April, 1953.

The methods of measurements and reductions are similar to those described in Part I and therefore no further comments are needed.

In Fig. 2, the distribution of the observed BOUGUER gravity anomalies in this district is shown by isoanomaly lines with 5 mgal intervals. What follow are some of the more important features which are noticed in the figure.

1) The Bouguer anomaly increases both towards north and south. On the Japan Sea coast, a positive anomaly of $48 \mathrm{mgal}$ was found, while on the Pacific coast, a positive anomaly of as large as $153 \mathrm{mgal}$ was found. Along the Japan Sea coast, the isoanomaly lines are roughly parallel to the coast line, except for the western part of the Bay of Wakasa.

2) It has been known geologically that the Median Tectonic Line runs about the middle of the island of Shikoku in WSW-ENE 


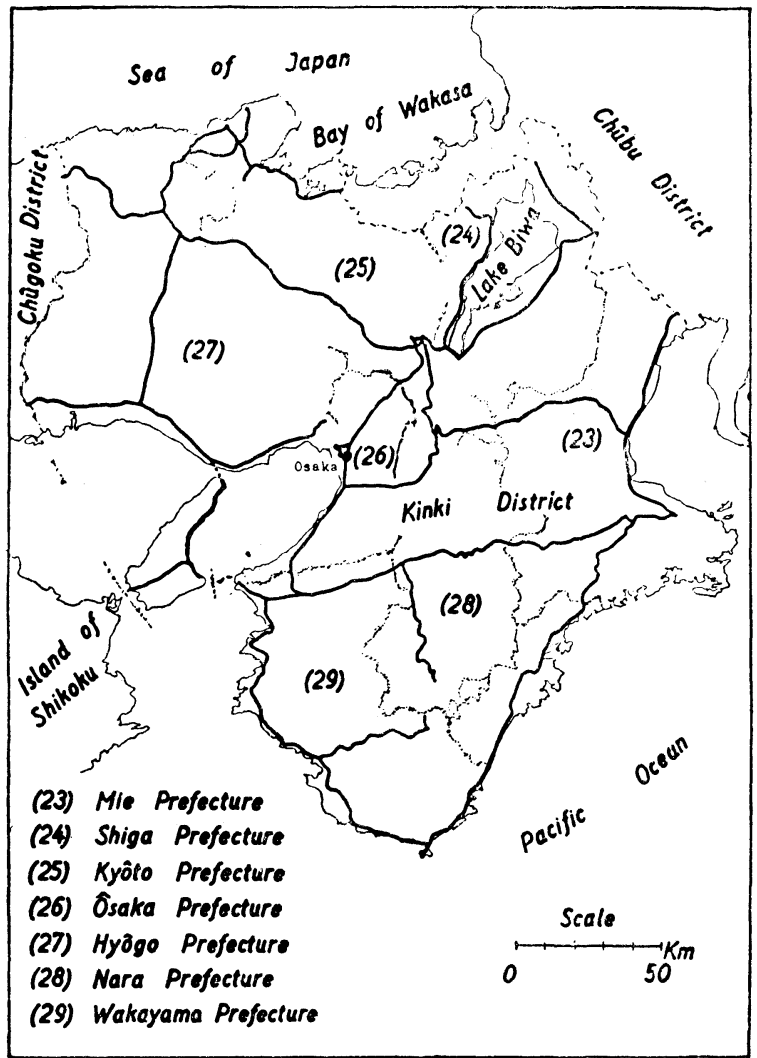

Fig. 1. Lines of precise levels in the Kinki district with prefecture boundaries

direction and keeping almost the same trend crosses the southern part of the Kinki district. It is interesting to note that the isoanomaly lines in the southern part of this district do not perfectly agree in trend with the geological structure of it. It is rather surprising that while the gravity anomalies in Shikoku so clearly suggest the anomalous subterranean density distribution which must be closely related to this tectonic line, those in the Kinki district apparently do not so likewise.

3) There is an area near the city of Ôsaka in which the anomaly is minimum. Probably this may be related to the Alluvial deposits with small densities on which the city is developed.

4) Almost perfectly conforming to the shape of Lake Biwa, there is an area of conspicuous negative anomaly. That Lake Biwa is a depression basin has been known from geological as well as from geomorphological studies. The strong negative gravity anomaly here suggests that the depression of the earth's crust is of-an amount which is larger than indicated by the present 


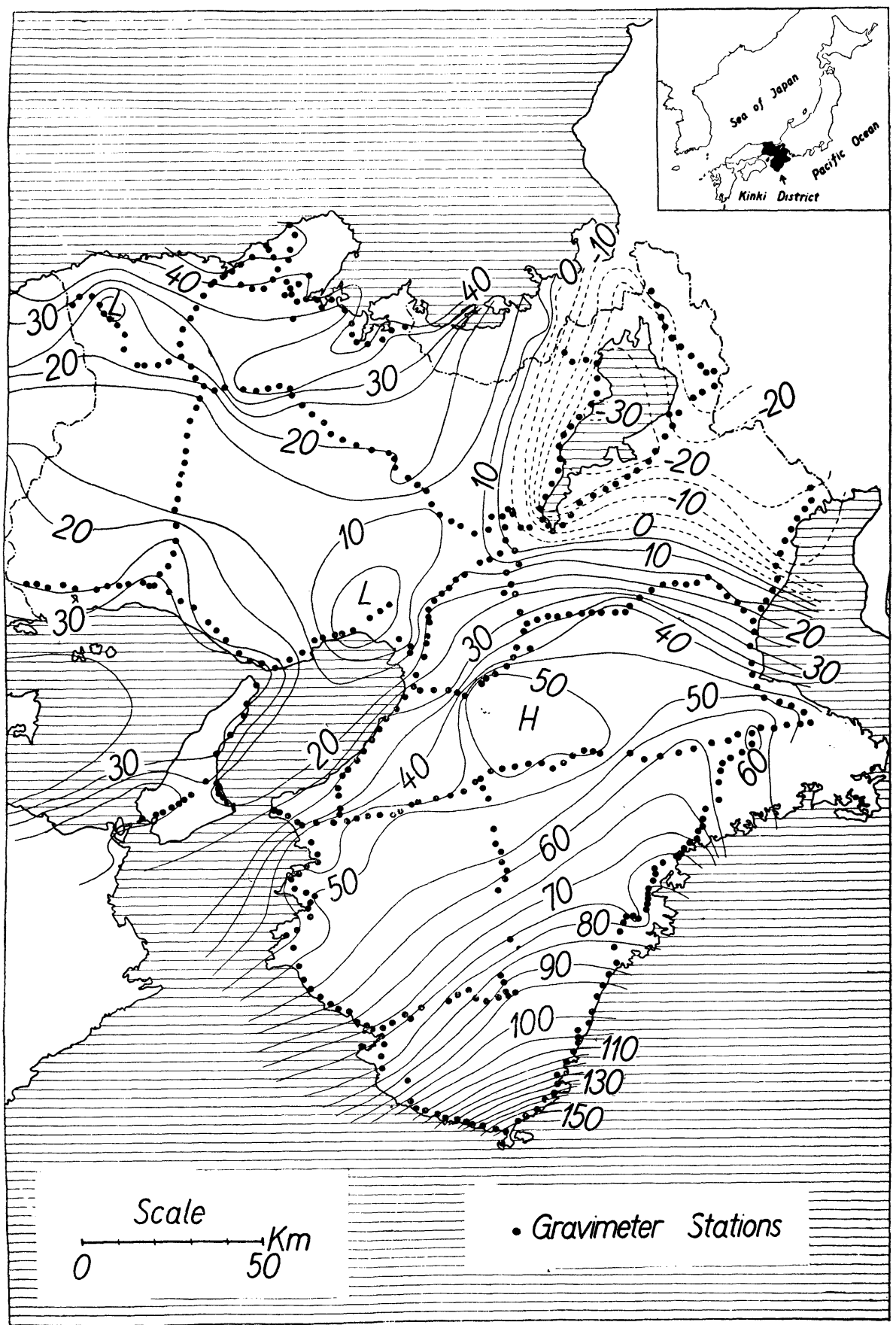

Fig. 2. Lines of equal Bouguer anomalies in the Kinki district (mgal) 


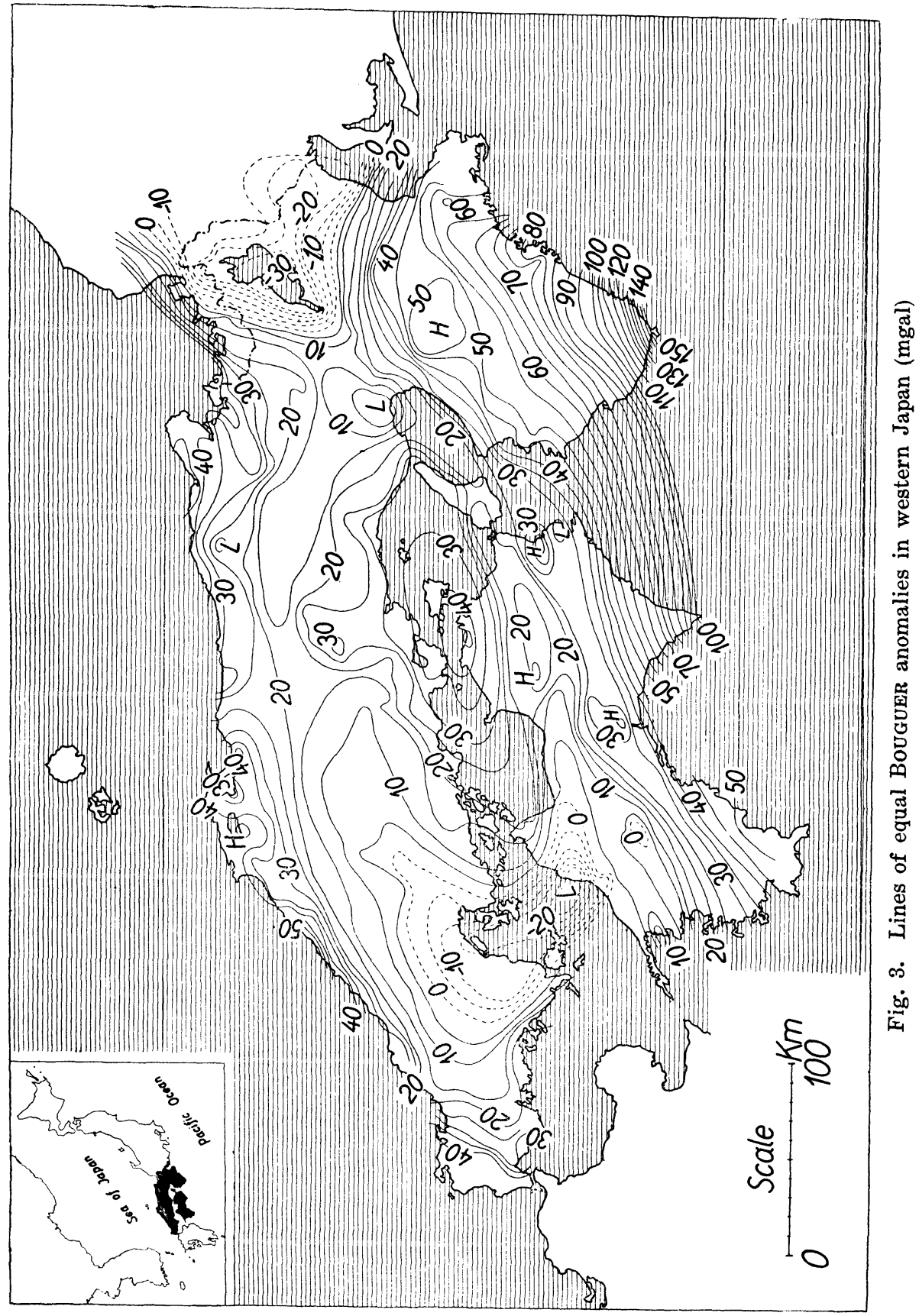


surface relief. Also the isoanomaly lines indicate that the dip of depression is steep on the west side while it is less so on the east side.

Lastly, Fig. 3 shows the distribution of the observed Bouguer anomalies in the western part of Honshû, the main island of Japan. This map was compiled from the maps given in Parts I, II and III for the districts of Shikoku, Chûgoku and Kinki respectively, on the basis of 1176 gravity measurements in total.

The details of the results and reductions will appear in the Bulletin of the Earthquake Research Institute. 